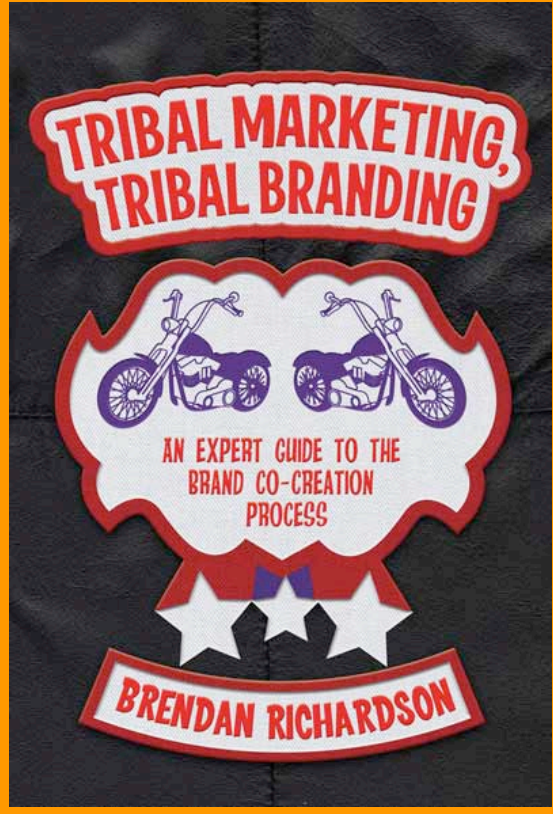

\title{
TRIBAL MARKETING, TRIBAL \\ BRANDING. AN EXPERT GUIDE TO \\ THE BRAND CO-CREATION \\ PROCESS
}

\section{Brendan Richardson}

Palgrave Macmillan, Hampshire, 2013

184 páginas

\section{Reseña por}

Paloma Sanz Marcos

Si bien el estudio de las Tribus Consumidoras se ha abordado extensamente desde perspectivas más bien psicológicas o sociológicas, poca literatura se ha generado desde el punto de vista del marketing. Esta obra del profesor Richardson se alza precisamente como una alternativa a esos estudios teóricos, y nos ofrece una guía práctica acerca de cómo implementar el Marketing Tribal y sus agentes (las Tribus Consumidoras) en el mundo profesional.

El capítulo inicial del libro se presenta como un marco teórico del que partir para comprender la naturaleza teórica en la que se ubica Richardson. Con un estilo sencillo y ameno, algo poco usual para los autores que suelen abordar estos temas, el autor desarrolla el concepto de Tribu Consumidora y la sitúa dentro de la corriente del marketing conocida como Marketing Tribal. Uno de los indicativos que caracterizan a estas tribus son las conexiones que se establecen entre los miembros que la conforman, lo que se conoce como Linking Value y que Richardson toma de Cova (1997) para apoyar toda su práctica en el Marketing Tribal. A pesar de no tratarse de una teoría con una base muy novedosa, sí se presenta como pionera en cuanto a formalidad práctica, ya que el capítulo avanza detallando las cuestiones que caracterizan a este link y presenta una tipología de tribus asociadas a marcas actuales que justifican la importancia de afirmar el mismo.

Cerrando este primer capítulo, bajo el epígrafe "Tribus consumidoras y Brand Communites: Similitudes y Diferencias", el autor expone una de las principales privaciones que manifiesta la obra. Tratándose de una guía de pretensión eminentemente práctica, se anhela un tratamiento diferenciado de ambos conceptos. Sin embargo, el autor reconoce que a pesar de que existen ciertas diferencias entre ambos términos, no acaba de asumir que 
verdaderamente haya claras delimitaciones y finaliza confesando que no pueden hacerse consideraciones de forma absoluta.

Los capítulos centrales de esta publicación ofrecen una aproximación de las técnicas necesarias para implementar este cuerpo teórico en el campo del Marketing Tribal. El objetivo principal del autor es que el lector comprenda la importancia de conocer el funcionamiento de dichas tribus, cómo se relacionan, qué tipo de comportamiento presentan y, sobre todo, qué relación construyen en torno a las marcas. Concretamente, se decanta por el desarrollo del Ethno-Marketing, un método que demuestra la eficacia de las técnicas etnográficas usadas en antropología para conocer el funcionamiento de las tribus. A partir de diversos ejemplos de marcas reconocidas como Harley Davidson, Mountain Dew o Red Bull, Richardson justifica el valor de emplear estas técnicas para la obtención de resultados satisfactorios que conecten el valor de la marca con estas comunidades.

La obra se cierra con dos capítulos finales que incitan a la reflexión por parte del lector. Por un lado, el octavo, dedicado a una reflexión ética acerca del Marketing Tribal, plantea una serie de recomendaciones acerca de cómo las investigaciones de carácter tribal tendría que llevarse a cabo. Desde las cuestiones más básicas de respeto hasta las advertencias de tipo legal que habría que considerar a la hora de llevar a cabo una investigación de este tipo. Por otro, el capítulo final sirve de cierre a toda la obra y anticipa algunas pinceladas de lo que podrían aportar todas estas nociones al marketing con el paso del tiempo. Finalmente, como si se tratara de un resumen de todo el libro, concluye con un apartado muy esquematizado de los puntos principales que el lector no debe olvidar.

En cuanto a las cuestiones formales, como adelanta el propio título de la publicación, se trata de una obra con carácter práctico que aspira a servir de guía. Por tanto, no es de extrañar que el final de cada capítulo se cierre con un resumen de las ideas más importantes a modo conclusivo. En cuanto al desarrollo de los mismos, encontramos gran cantidad de epígrafes que facilitan la lectura y limitan la temática. Además, se presentan numerosas tablas de contenidos que esquematizan el grueso de la información contribuyendo a la comprensión del contenido.

Sin duda, Tribal Marketing, Tribal Branding aporta una perspectiva funcionalista y clara de lo que suponen las tribus consumidoras. Presenta, por tanto, un enfoque que se hace necesario en el contexto de toda la literatura de estilo posmoderno que existe en la academia. Si es cierto que toda esa literatura ha establecido las bases de las que el autor se nutre para desarrollar su tesis, esta nueva publicación consigue presentarnos un trabajo de brillante nitidez que supone un paradigma a seguir para futuras investigaciones sobre el tema. 